\title{
West African equatorial ionospheric parameters climatology based on Ouagadougou ionosonde station data from June 1966 to February 1998
}

\author{
F. Ouattara ${ }^{1,{ }^{*}}$, C. Amory-Mazaudier ${ }^{2, *}$, R. Fleury ${ }^{3, *}$, P. Lassudrie Duchesne ${ }^{3, *}$, P. Vila ${ }^{4, *}$, and M. Petitdidier ${ }^{5, *}$ \\ ${ }^{1}$ Ecole Normale Supérieure, Université de Koudougou, BP 376 Koudougou, Burkina Faso \\ ${ }^{2}$ LPP/CNRS/UPMC, 4 Avenue de Neptune 94107 Saint-Maur-des-Fossés, France \\ ${ }^{3}$ ENST Bretagne, Technopole Brest Iroise, 29239 Brest, France \\ ${ }^{4}$ retired from: CETP, 4 Avenue de Neptune, 94107 Saint-Maur-des-Fossés, France \\ ${ }^{5}$ LATMOS/IPSL/CNRS, 10 Avenue de l'Europe 78140 Velizy, France \\ *also at: GIRGEA (Groupe International de Recherche en Géophysique Europe Afrique), LPP/CNRS/UPMC, 4 Avenue de \\ Neptune 94107 Saint-Maur-des-Fossés, France
}

Received: 17 December 2008 - Revised: 8 April 2009 - Accepted: 11 June 2009 - Published: 23 June 2009

\begin{abstract}
This study is the first which gives the climatology of West African equatorial ionosphere by using Ouagadougou station through three solar cycles. It has permitted to show the complete morphology of ionosphere parameters by analyzing yearly variation, solar cycle and geomagnetic activity, seasonal evolution and diurnal development. This work shows that almost all ionospheric parameters have 11-year solar cycle evolution. Seasonal variation shows that only $f_{o} \mathrm{~F} 2$ exhibits annual, winter and semiannual anomaly. $f o \mathrm{~F} 2$ seasonal variation has permitted us to identify and characterize solar events effects on F2 layer in this area. In fact (1) during quiet geomagnetic condition $f o \mathrm{~F} 2$ presents winter and semiannual anomalies asymmetric peaks in March/April and October. (2) The absence of winter anomaly and the presence of equinoctial peaks are the most visible effects of fluctuating activity in $f o F 2$ seasonal time profiles. (3) Solar wind shock activity does not modify the profile of $f o \mathrm{~F} 2$ but increases ionization. (4) The absence of asymmetry peaks, the location of the peaks in March and October and the increase of ionization characterize recurrent storm activity. F1 layers shows increasing trend from cycle 20 to cycle 21. Moreover, E layer parameters seasonal variations exhibit complex structure. It seems impossible to detect fluctuating activity effect in $\mathrm{E}$ layer parameters seasonal variations but shock activity and wind stream activity act to decrease $\mathrm{E}$ layer ionization. It can be seen from Es layer parameters seasonal variations that wind stream activity effect is fairly in-
\end{abstract}

Correspondence to: F. Ouattara

(fojals@yahoo.fr) dependent of solar cycle. E and Es layers critical frequencies and virtual heights diurnal variations let us see the effects of the greenhouse gases in these layers.

Keywords. History of geophysics (Solar-planetary relationships) - Ionosphere (Equatorial ionosphere) - Meteorology and atmospheric dynamics (Climatology)

\section{Introduction}

The successful transatlantic radio transmissions performed by Marconi in 1901 have led Kennelly and Heaviside to hypothesize the existence of some reflecting layer in the atmosphere. This reflecting layer has been confirmed by the experiments of Appleton and Barnett (1926) and also by the experiments of Breit and Tuve (1926). Rishbeth (2001) and Schröder's (2002) recent reviews tell us something about the history of solar-terrestrial physics.

According to Hall and Hansen (2003) these first ionospheric soundings were intended not only to establish but also to map for a little understanding of Kennely-Heaviside layer (later to be the E-layer together with the Appleton or F-layer).

From 1925 until now the development of radio communications using ground-to-ground communication via ionosphere using HF radio propagation and from ground-tosatellite through the ionosphere at higher frequencies was carried out. The peak $\mathrm{F}$ region electron density $(\mathrm{NmF} 2)$ or critical frequency $(f o \mathrm{~F} 2)$ is an important parameter as

Published by Copernicus Publications on behalf of the European Geosciences Union. 
Table 1. Evolution of different correlation coefficients with solar activity.

\begin{tabular}{ccccc}
\hline Cycles & & 20 & 21 & 22 \\
\hline & $f o \mathrm{~F} 2$ & 0.977 & 0.973 & 0.948 \\
& $h^{\prime} \mathrm{F} 2$ & 0.952 & 0.607 & 0.122 \\
& $f o \mathrm{~F} 1$ & 0.850 & 0.944 & 0.970 \\
& $h^{\prime} \mathrm{F} 1$ & 0.510 & 0.792 & 0.896 \\
Correlation coefficient & $f o \mathrm{E}$ & 0.726 & 0.169 & 0.560 \\
& $h^{\prime} \mathrm{E}$ & 0.891 & 0.073 & 0.323 \\
& $f_{o} \mathrm{Es}$ & 0.716 & 0.421 & 0.041 \\
& $h^{\prime} \mathrm{Es}$ & 0.427 & 0.678 & 0.192 \\
\hline
\end{tabular}

it determines the maximum usable frequency (MUF) for oblique propagation of radio waves.

In the 1920s climatic change was a concept that received little attention. An important question is to determine how ionospheric sounding can be used to foster for climate research. A most accessible insight is provided by Rishbeth and Clilverd (1999) and more depth is given by Roble and Dickinson (1989).

Bremer (2004) used more than 100 different ionosonde stations data to investigate long-term trends in the ionosphere. He found that there is a lowering of $h^{\prime} \mathrm{E}$ and the increase of $f o \mathrm{E}$ and $f o \mathrm{~F} 1$. Such results may be due to the increasing of the atmosphere greenhouse gases (Robble and Dickinson, 1989; Rishbeth, 1990).

Zhang et al. (2005) gave ionospheric climatology from long-term databases of multiple incoherent scatter radars. By analyzing annual ionospheric variations in electron density and ion temperature, the authors showed that annual and semiannual components exhibit clearly latitudinal, longitudinal, and altitudinal dependency. In West African sectors there is a lack of ionosphere parameter measurements studies. In the past only few ionosondes worked: Dakar (lat: $14.8 \mathrm{~N}$; long: 342.6E; dip: +5.53), Ouagadougou $\left(12.4^{\circ} \mathrm{N}, 358.5 \mathrm{E}\right.$; dip:+1.45), Tamanrasset (lat: $22.80 \mathrm{~N}$; long:354.47; dip: +14.57), Ibadan (lat:7.43 $\mathrm{N}$; long: 356.10E; dip:-5.01) and recently Korhogo (lat: $9.3^{\circ} \mathrm{N}$; long: $354.62 \mathrm{E}$; dip:-2.25). In equatorial region only the Ouagadougou station of ionospheric sounding worked during $\sim 3$ solar cycles (from June 1966 to February 1998). It is important to note that there are some works which used these African equatorial stations data (Adeniyi and Adimula, 1995; Adeniyi and Radicella, 1998a, b; Bilitza et al., 2004; Obrou, 2008) in order to model or to analyse ionosphere parameters diurnal variation. The present work analyses not only the diurnal variation of the mainly ionosonde parameters (virtual heights and critical frequencies of F2, F1, E and Es layers) of Ouagadougou ionosonde station but also their yearly and seasonal variations throughout three solar cycles. Section 2 gives the data sets used and the data analysis under- taken. Section 3 reports on the analysis of yearly, solar cycle, geomagnetic activity, seasonal and diurnal variations. The last section is devoted to our main results and discussion. In order to avoid repetitions, we present detailed results in figures next to the corresponding text, where captions describe the observed features. We list our most original results at the end of the paper.

\section{Data sets and data analysis}

To establish climatology of the equatorial ionosphere parameters in West Africa, we use Ouagadougou station ionosonde data. Ouagadougou station is located near the magnetic equator in the trough of the Equatorial Ionisation Anomaly $\left(12.4^{\circ} \mathrm{N}, 358.5 \mathrm{E}\right.$; dip: +1.45) and operated from June 1966 to February 1998. The data are provided by Ecole Nationale Supérieure de Télécommunication de Bretagne (ENST Bretagne) database and concern hourly values for critical frequencies of F2 layer ( $f o \mathrm{~F} 2), \mathrm{F} 1$ layer $(f o \mathrm{~F} 1)$, E layer $(f o \mathrm{E})$ and Es layer ( $f o$ Es) and virtual height of those parameters. Our work describes the behaviour of ionospheric parameters in this area where we analyse yearly, solar cycle, seasonal and diurnal variations of the ionospheric parameters during three solar cycles $(20,21$ and 22). Error bars $(\sigma=\sqrt{V}, V$ : variance) provide estimation of the uncertainty in the ionospheric parameters. For seasonal study, we assume (1) November through February as winter months, (2) May through August as summer months and (3) March/April and September/October as equinoctial months. The study is performed for the different phases of solar cycles. We distinguish four parts (minimum phase, increasing phase, maximum phase and decreasing phase). The maximum phase years are obtained by assuming $R z>100$ and minimum phase years are given by $R z<20$. Increasing phase years are years with $20 \leq R_{z} \leq 100$, and decreasing phase years are years with $100 \geq R_{z} \geq 20$. By taking into account the above subdivisions and by reference of the period of the available data of $f_{o} \mathrm{~F} 2$, the retained years are respectively (1) 1976 and 1986 for solar minimum of cycles 21 and 22; (2) 19661967, 1976-1978, 1986-1988 for solar increasing phase of cycles 20, 21 and 22; (3) 1968-1970, 1979-1982, 1989 for solar maximum of cycles 20, 21 and 22 and (4) 19711976, 1983-1986, 1992-1996 for solar decreasing phase of cycles 20,21 and 22 .

One of our objectives is to show the impact of the different geomagnetic activity classes in ionosphere parameters. It is important to indicate that Legrand and Simon (1989) defined geomagnetic classes and gave their occurrences through solar cycle. The comparison between their occurrence years (Table 2 of Legrand and Simon, 1989) and our solar cycle phase years (given above) leads us to conclude that we are able to determine the impact of each geomagnetic class of activity by our subdivision. 
Table 2. Ionosphere diurnal profiles characteristics and properties.

\begin{tabular}{cl}
\hline Ionosphere parameters & Profiles characteristics and properties \\
\hline$f_{o \mathrm{~F} 2}$ & $\begin{array}{l}\text { Noon bite out profiles with asymmetric peaks. During mini- } \\
\text { mum, increasing and decreasing phases morning peak is greater } \\
\text { than evening one. During maximum phase evening is greater } \\
\text { than morning one. }\end{array}$ \\
& $\begin{array}{l}\text { Parabolic profile during minimum, increasing and decreasing } \\
\text { phases. }\end{array}$ \\
& $\begin{array}{l}\text { Complex structure during maximum phase } \\
h^{\prime} \mathrm{F} 2\end{array}$ \\
& "Basin" profile with asymmetric peaks. Evening peak are \\
& greater than morning one. The asymmetry is more pronounced \\
& during maximum phase \\
& Parabolic profiles \\
& "Boat" profile \\
$f^{\prime} \mathrm{F} 1$ & Parabolic profile \\
$h^{\prime} \mathrm{E}$ & "Wave" profile with morning, evening and night peaks. Morning \\
$f_{o \mathrm{E} s}$ & and evening peak are more pronounced. Morning peak is the \\
& highest.
\end{tabular}

In this paper, arithmetical mean values obtained from day-time hourly values of ionosphere parameters are used for studying diurnal variation. Seasonal and yearly evolutions are obtained by using respectively arithmetical mean values of monthly and yearly values. Solar cycle variation is described by studying the correlation coefficient between each ionosphere parameter values and sunspot number. This yearly treatment consists in plotting together yearly ionosphere parameters with sunspot yearly number. In these graphs error bars give the percentage of errors in the appreciation of the parameters variations. After yearly variation analysis, solar cycle and geomagnetic activity variations are studied. The distinction between quiet and disturbed conditions is made by using am index values because it is a planetary index by itself. The magnetic am indices are used to characterize the magnetic conditions: $a m<20 \mathrm{nT}$ correspond to magnetic quiet days and am $\geq 20$ nT to magnetic disturbed days. Seasonal and diurnal variations are also described.

\section{Results presentation}

\subsection{Solar cycle variation}

In Fig. 1 are superimposed the yearly ionospheric parameters and the yearly sunspot number evolution. In Fig. 1, the left panel represents the variation of critical frequencies derived from Ouagadougou ionograms during three solar cycles 20, 21, 22. The right panels show the dependence of virtual heights on solar sunspot values for the same solar cy- cles. In Fig. 1 one can observe that all ionosphere parameters behaviour changes each 11-year. Panel a exhibits parallel behaviour between annual critical frequency of F2 layer ( $f o F 2$ ) and sunspot number; In panel (c), we observe also very good correlation between annual critical frequency of F1 layer and annual sunspot number. Panel (e) shows the decrease of foE with sunspot number from 1966 to 1978. 11-year running arithmetic mean with one year step gives 0.755 as an anti correlation regression coefficient. The $h^{\prime} \mathrm{F} 2$ diagram (panel b) exhibits very fair anti correlation with sunspot number; $h^{\prime} \mathrm{F} 2$ shows two increasing intervals: one from 1967 to 1977 and the other from 1980 to 1996 . Panel (d) shows good correlation between $h^{\prime} \mathrm{F} 1$ and sunspot number particularly for the two last solar cycles. In panels (f) and (h), $h^{\prime} \mathrm{E}$ and $h^{\prime} \mathrm{Es}$ are not correlated with sunspot.

Table 1 gives cycle by cycle the evolution of the correlation coefficient of ionosphere parameters with sunspots. This table shows that the correlation coefficient of foF 2 decreases with solar cycle (from 0.977 for cycle 20 to 0.948 for cycle 22) while $h^{\prime} \mathrm{F} 2$ anti correlation coefficient decreases from 0.952 for cycle 20 to 0.607 for cycle 21 and falls from the latest value to 0.122 for cycle 22. foF 1 correlation coefficient increases with solar cycle (from 0.850 for cycle 20 to 0.970 for cycle 22) likewise that of $h^{\prime} \mathrm{F} 1$ (from 0.510 for cycle 20 to 0.896 for cycle 22 ). From 0.726 for cycle $20 \mathrm{foE}$ correlation coefficient decreases appreciably to 0.169 for cycle 21 and rise from 0.169 for cycle 21 to 0.560 for cycle 22 likewise from 0.891 for cycle $20, h^{\prime}$ E correlation coefficient decreases significantly to 0.073 for cycle 21 and increases from the latest value to 0.323 for cycle 22. foEs correlation 


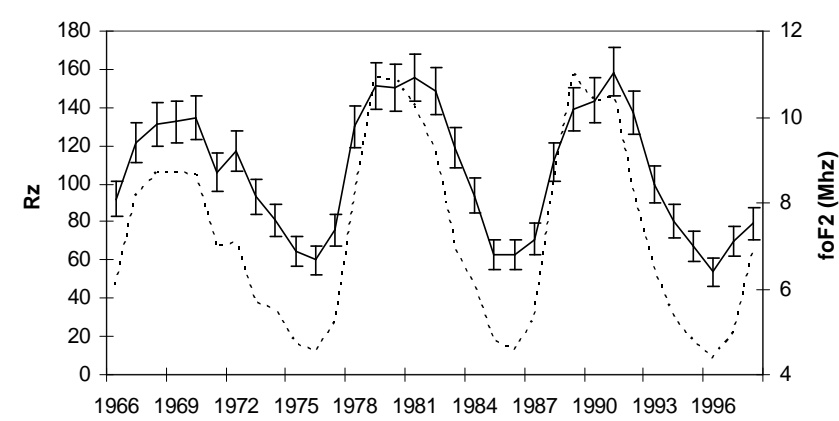

(a)

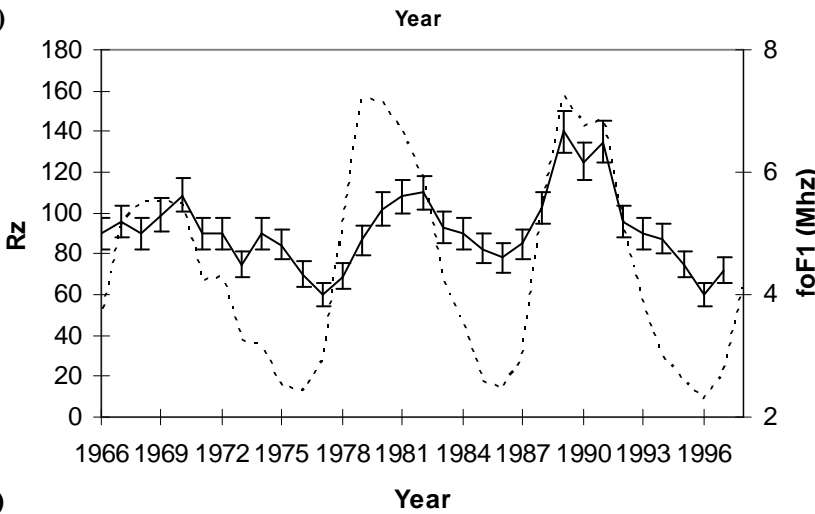

(c)

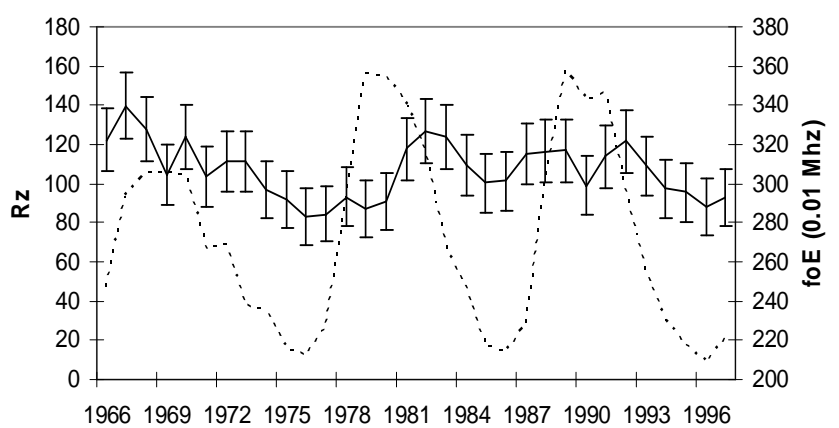

(e)

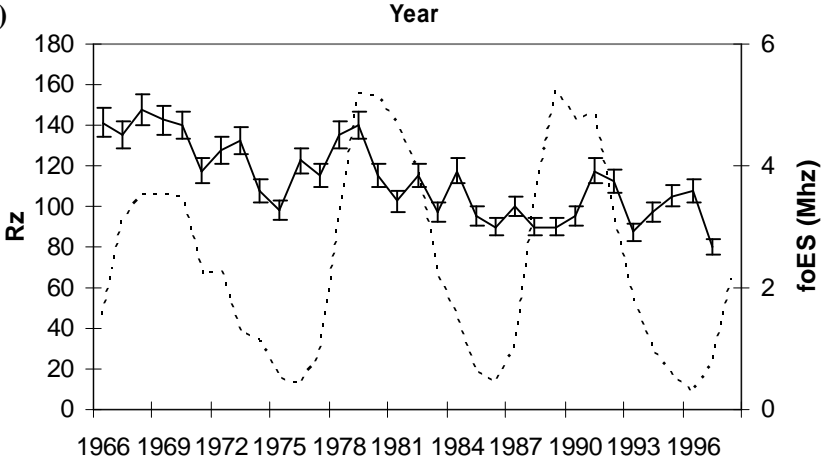

(g)

Year

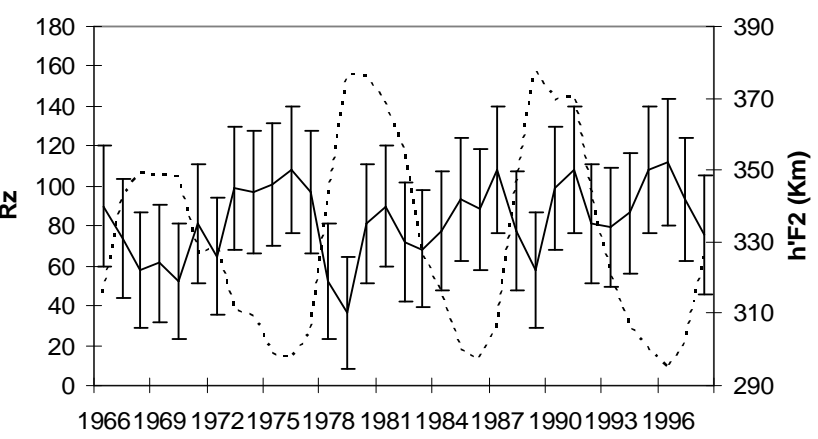

(b)

Year

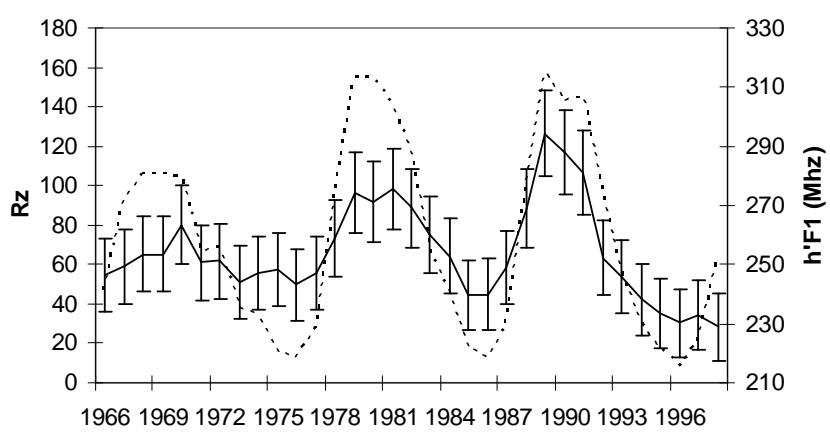

(d)

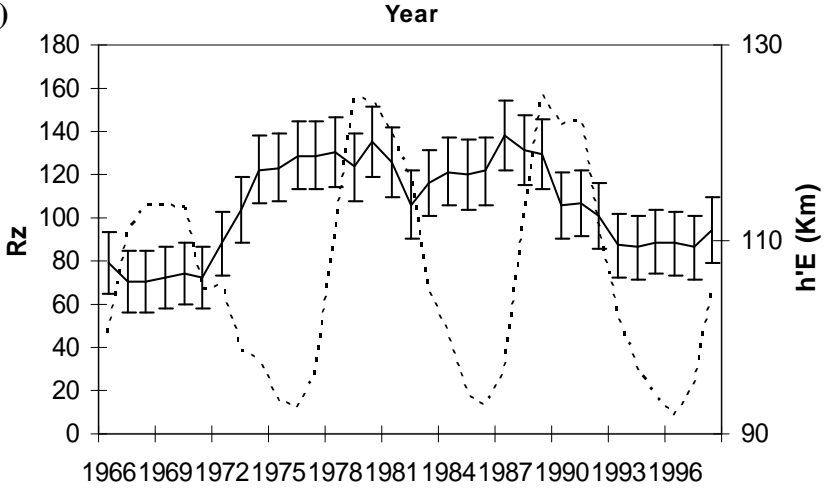

(f)

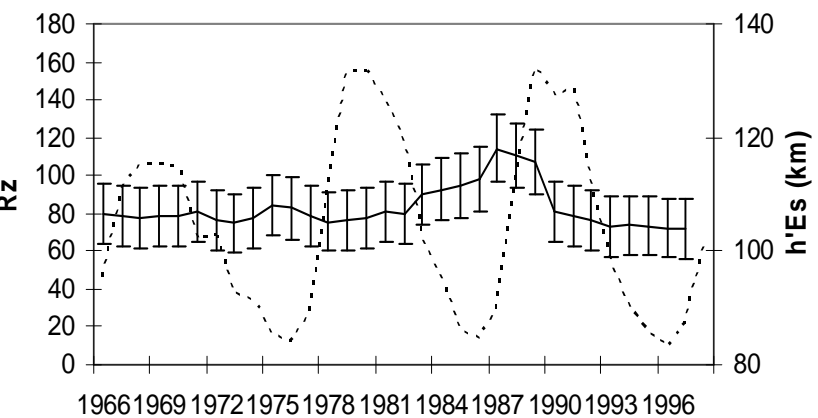

(h)

Year

Fig. 1. Yearly variation of ionospheric parameters (solid line) such as critical frequencies (left row) and virtual heights (right row) with sunspot number (dotted line). The vertical bars indicate standards deviation. First line (panels a and b): parameters of layer F2. Second line (panels $\mathbf{c}$ and $\mathbf{d}$ ) parameters of layer F1. Third line (panels e and f): parameters of layer E. Fourth line (panels $\mathbf{g}$ and $\mathbf{h}$ ) parameters of layer Es. 

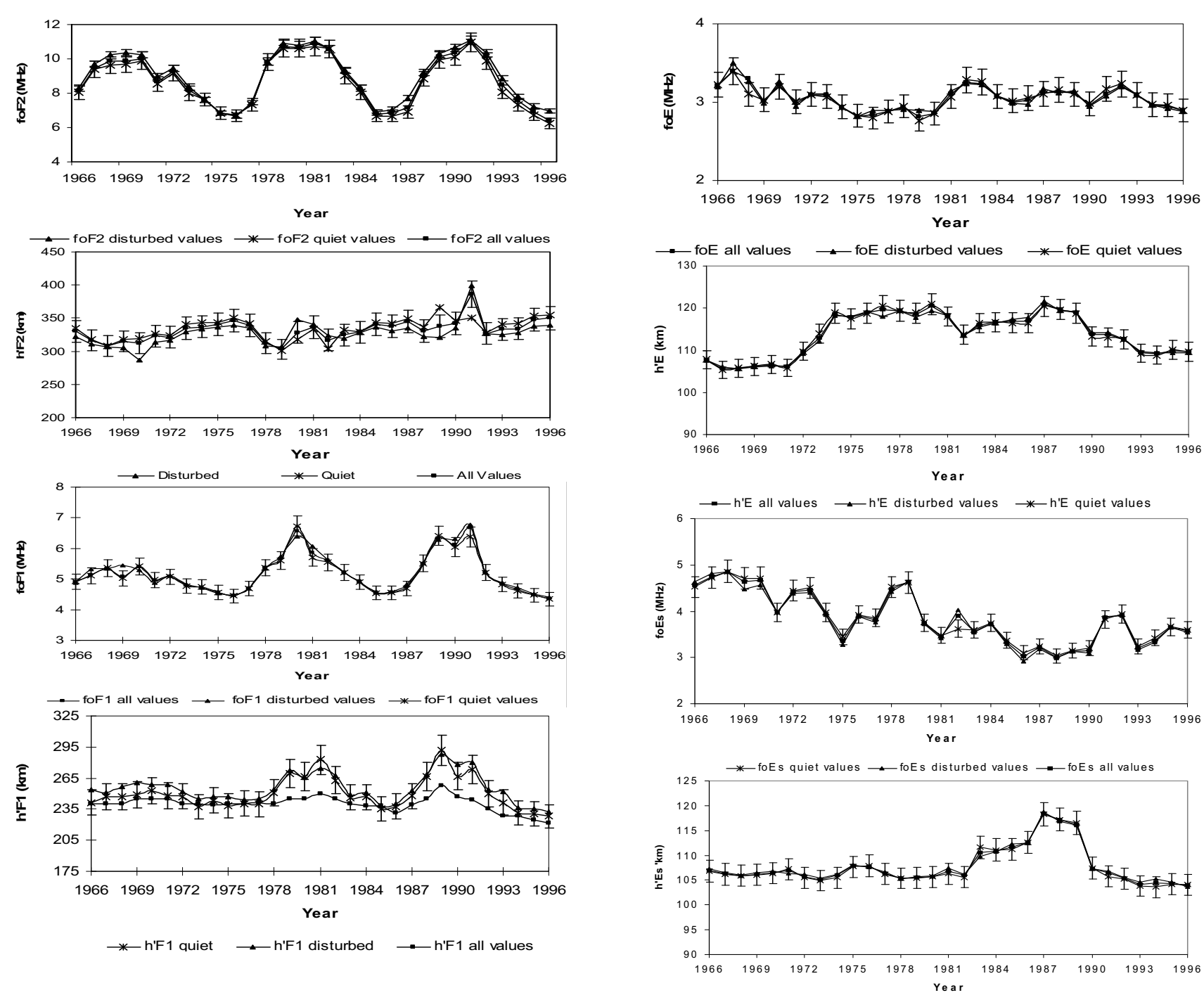

Fig. 2a. From top to bottom: the annual variation, from 1966 to 1996, of $f o \mathrm{~F} 2$ (panel a), of $h^{\prime} \mathrm{F} 2$ (panel b), of $f o \mathrm{~F} 1$ (panel c) and of $h^{\prime} \mathrm{F} 1$ (panel d) for whole values (line with square), quiet values (line with star) and disturbed values (line with triangle).

coefficient decreases from 0.716 for cycle 20 to 0.421 for cycle 21 and from 0.421 for cycle 21 it decreases significantly to 0.041 for cycle 22 while $h^{\prime}$ Es correlation coefficient increases from 0.427 for cycle 20 to 0.678 for cycle 21 and practically disappears from 0.678 for cycle 21 to 0.192 for cycle 22.

It emerges from the observations that ionosphere parameters exhibit different time behaviours. It is shown also that among all the ionosphere parameters only $f o \mathrm{~F} 2$ and $h^{\prime} \mathrm{F} 1$ follow the solar cycle. From this observation the better correlation of $h^{\prime} \mathrm{F} 1$ with sunspot than $h^{\prime} \mathrm{F} 2$ emerges. It is well known that (1) poloïdal and toroïdal solar magnetic fields manage solar wind behaviour and sunspot behaviour respectively (Simon and legrand, 1989) and (2) ionosphere solar energy in the form of electromagnetic wave radiations prin-

cipally in the UV/EUV range is the only ionizing agent of atmosphere (Chapman, 1931). The diurnal, seasonal, spatial and solar cycle variations of the ion density of the $\mathrm{E}$ and $\mathrm{Fl}$ layers can be explained on this assumption (Davies, 1965). Solar wind may also be responsible for contributing part of the energy required for the production of the F2 layer ionization (Chaman, 1997, 1998). For that, F2 layer depends on the both solar magnetic field components while F1 layer does not depend on poloïdal component. The double dependence of F2 layer on one hand to UV and EV and on the other hand to solar poloïdal component may be explained why F1 layer is better correlated with sunspot than $h^{\prime} \mathrm{F} 2$.

Moreover $h^{\prime} \mathrm{F} 1$ increases with solar cycle and the foF 2 increases when solar cycle increases. According to these observations, the correlation with the solar sunspot is 


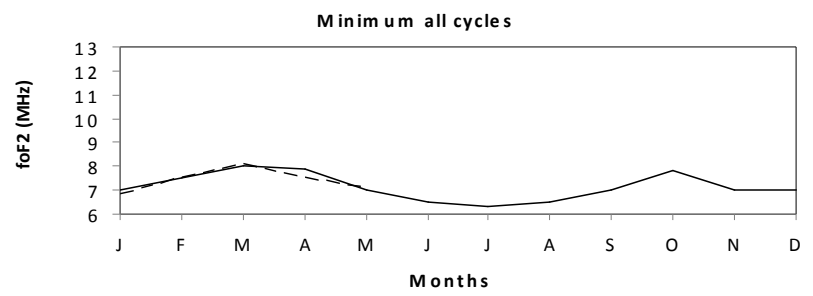

(a)

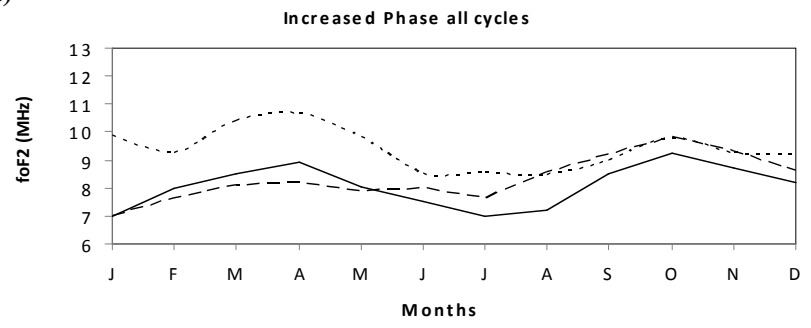

(b)
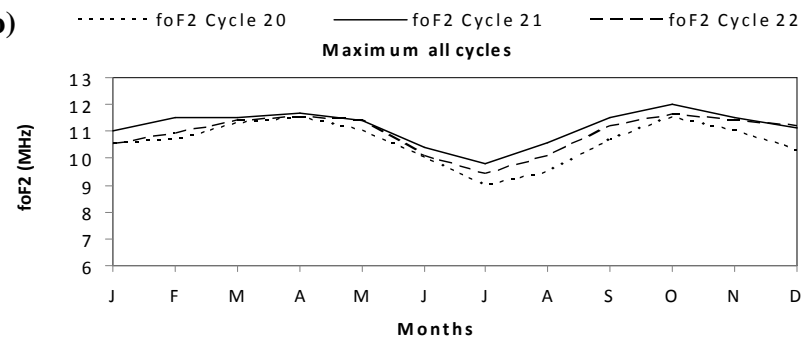

(c)
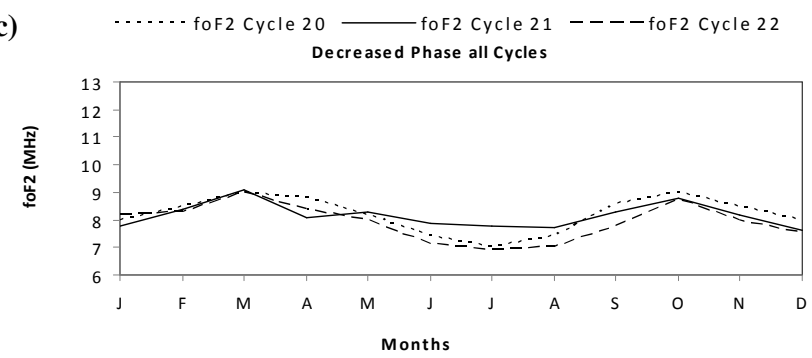

(d)

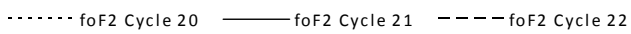

Fig. 3. From top to bottom: seasonal variation $f_{o} \mathrm{~F} 2$ during minimum phase (panel a), increased phase (panel b), maximum phase (panel c) and decreased phase (panel d) for three solar cycles: cycle 20 (dotted line); cycle 21 (continues line); cycle 22 (broken line).

contrasted. Only three parameters exhibit parallel behaviour with sunspot cycle during the three cycles: the critical frequencies of layers F2 and F1 (Fig. 1a and c) and the virtual height of F1 layer (Fig. 1d). For F1 layer $h^{\prime} \mathrm{F} 1$ and foF1 correlation coefficients increase as solar cycle increases while it is the reverse situation for F2 layer. The variations of $\mathrm{E}$ and Es layers are different. It emerges from Fig. 1f that from 1966 to 1980 , the E layer rises from $108 \mathrm{~km}$ to $120 \mathrm{~km}$ and afterward decreases until $114 \mathrm{~km}$ in 1982 and arises from this value until $121 \mathrm{~km}$ in 1987 while $h^{\prime}$ Es (Fig. 1h) is almost stable $(106 \mathrm{~km})$ from 1966 to 1982 and after rises until $118 \mathrm{~km}$ in 1987. From 1987 to 1993 Es layer decreases from $118 \mathrm{~km}$ to $104 \mathrm{~km}$ and remains almost stable $(104 \mathrm{~km})$ until 1996. Figure $1 \mathrm{~g}$ presents two decreasing trends. The latter decreasing trend begins at $5 \mathrm{MHz}$ (1979) and finishes at $3 \mathrm{MHz}$ (1990) while the former begins at $5 \mathrm{MHz}$ (1966) and ends at $4 \mathrm{MHz}$ (1971).

\subsection{Solar cycle and geomagnetic activity}

Figure 2 is devoted to yearly variation of ionosphere parameters during geomagnetic quiet condition (day of am $<20 \mathrm{nT}$ ), during geomagnetic disturbed condition (day of $a m>=20 \mathrm{nT}$ ) and for both geomagnetic quiet and disturbed conditions. In Fig. 2a from top to bottom are given the yearly variations of $f o \mathrm{~F} 2, h^{\prime} \mathrm{F} 2, f o \mathrm{~F} 1$ and $h^{\prime} \mathrm{F} 1$ respectively. From top to bottom, Fig. 2b shows yearly variations of $f o \mathrm{E}, h^{\prime} \mathrm{E}$, foEs and $h^{\prime}$ Es respectively. Error bars in Fig. 2 permit us to conclude that geomagnetic effect during solar cycle 21 and 22 is only perceptible for $h^{\prime} \mathrm{F} 1$ (Fig. 2a panel 4).

\subsection{Seasonal variation}

In this section we study seasonal evolution of ionosphere parameters. Here we take into account different phases of solar cycle: minimum phase, increasing phase, maximum phase and decreasing phase. We firstly analyse the evolution of critical frequencies and secondly the evolution of virtual heights. Note that only parameters which present significant monthly evolution will be presented. It concerns F2, E and Es parameters.

Figure 3 presents monthly evolution of $f o \mathrm{~F} 2$ under four solar conditions (minimum, increased, maximum and decreased phases). All panels exhibit the semiannual anomaly: highest values at equinox months and minima at solstice months (Huang and Cheng, 1996; Arauje-Pradere, 1997; Zou et al., 2000; Rishbeth et al., 2000). A second peak of $f o F 2$ occurs always in October whereas the first peak of $f o \mathrm{~F} 2$ appears in April for increasing phase and maximum phase and in March during minimum phase and decreasing phase. For all panels, the winter values of $f o \mathrm{~F} 2$ are greater than summer ones. This fact was previously observed by Arauje-Pradere (1997), Zou et al. (2000), and Rishbeth et al. (2000). This anomaly is called the winter anomaly (Rishbeth and Garriott, 1969). For increasing phase and decreasing phase the spring peak of $f_{o} \mathrm{~F} 2$ is greater than the autumn peak. During solar maximum the autumn peak of $f o \mathrm{~F} 2$ is greater than the summer one. $f o \mathrm{~F} 2$ variations (panels $\mathrm{b}$ and $\mathrm{d}$ ) show an annual asymmetry which is sometimes called the "annual" or "nonseasonal" anomaly. Annual asymmetry is the global excess of F2-layer ionization in December-January as compared to June-July (Rishbeth and Müller-Wodarg, 2006). All graphs appear to follow similar variations except for that in panel $b$ where a gap exists between critical frequency of cycle 20 and the other frequencies during its increasing phase. This must be due to the lack of data because this phase started since 1964 and our data have been available since June 1966. From 


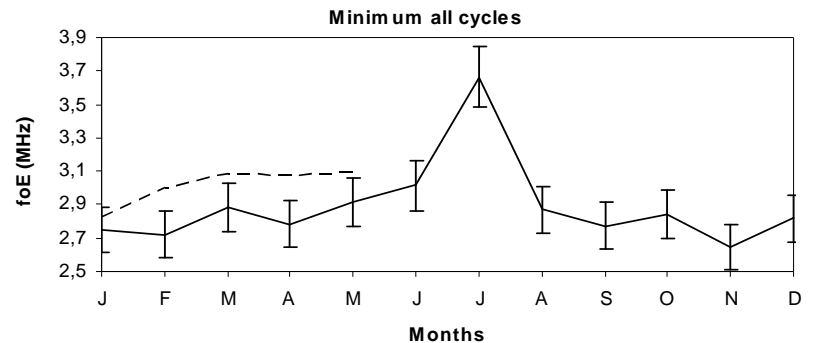

(a)

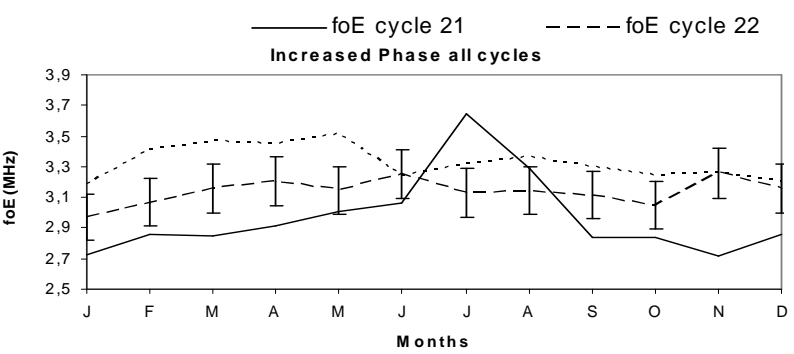

(b)
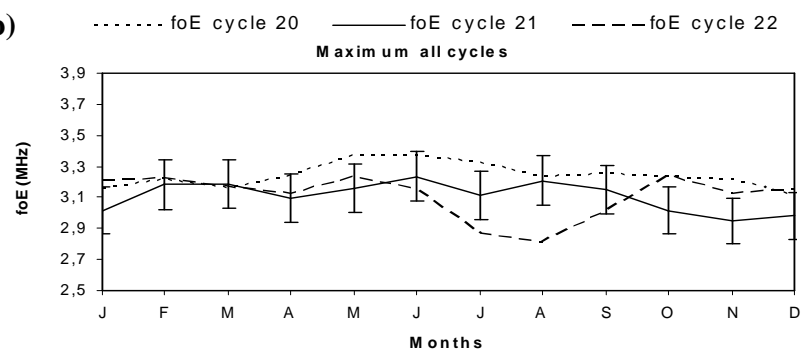

(c)
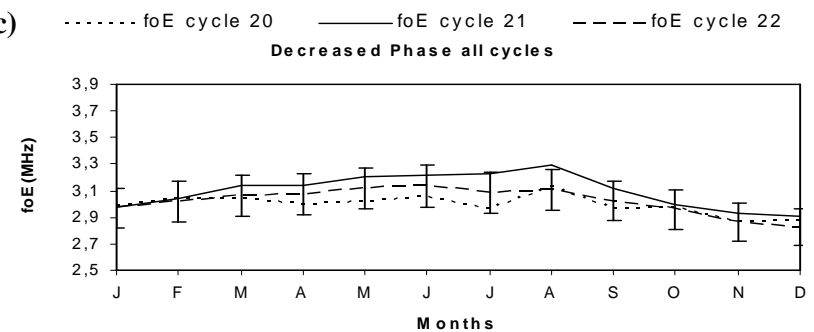

(d)

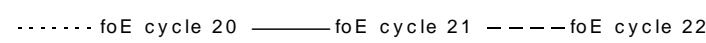

Fig. 4. Similar to Fig. 3 for $f o \mathrm{E}$.

panel (a) to panel (d) we note that seasonal ionization grows from minimum phase to maximum phase and decreases from maximum to the decreasing phase. Decreasing phase seasonal ionization and increasing phase seasonal ionization are not symmetric compared with maximum phase seasonal ionization. Per cycle, it can be noted that seasonal foF2 increases differently from minimum phase.

In Fig. 4 we present monthly variation of $f_{o} \mathrm{E}$ under four solar conditions (minimum, increased, maximum and decreased phases). Over the solar cycle, from minimum phase to decreasing phase, the seasonal ionisation of $E$ layer presents different behaviours without anomalies. All seasonal graphs present three maxima. By taking into account the error bars shown in Fig. 4 one can conclude that only during declining phase (panel d) all seasonal graphs present similar variations.

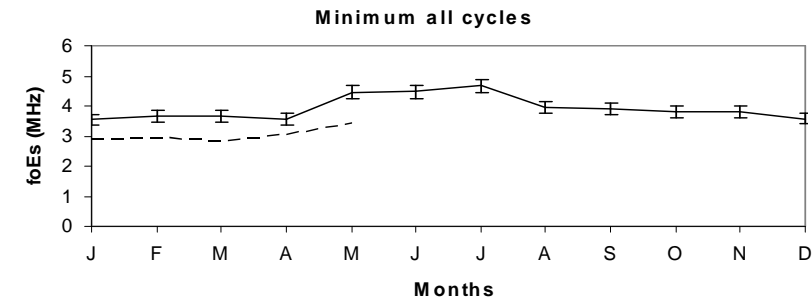

(a)

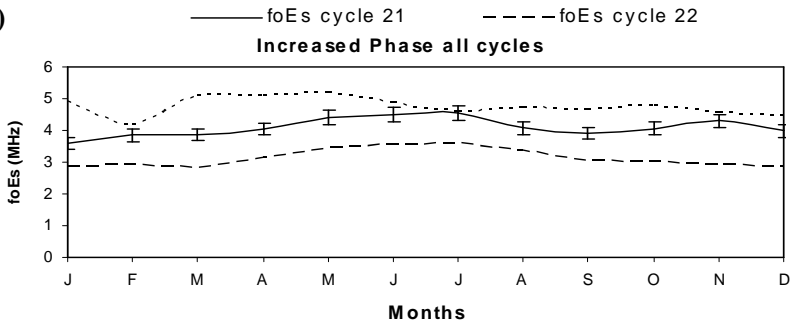

(b) $\quad \ldots \ldots$ foEs cycle $20 \_$foEs cycle $21 \quad---$ foEs cycle 22

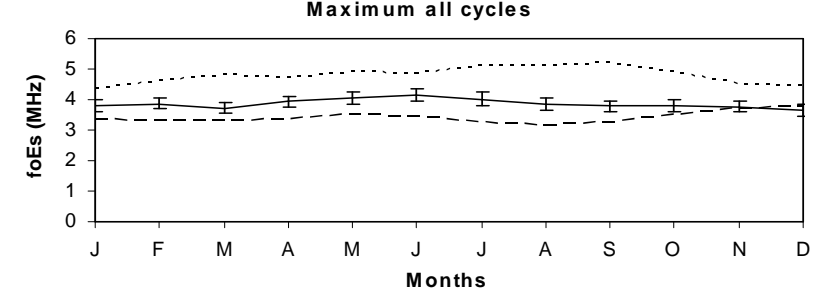

(c)
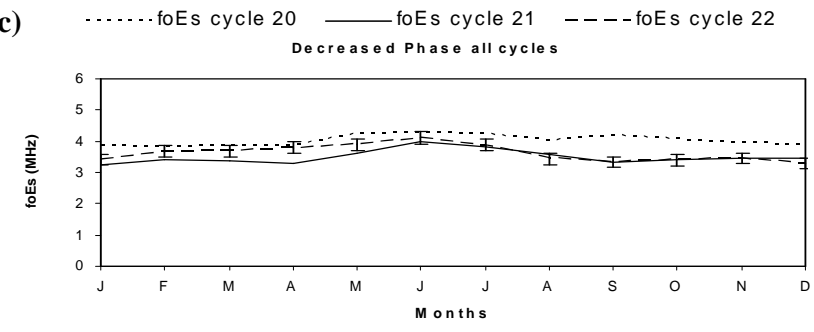

(d)

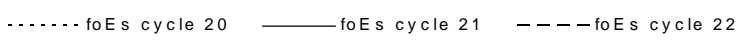

Fig. 5. Similar to Fig. 3 for $f o$ Es.

Figure 5 presents seasonal variation of $f o$ Es during four solar phases. On this figure the seasonal graphs exhibit three maxima. By considering the error bars it can be seen that through the year from panel (a) (solar minimum phase) to panel (c) (solar maximum phase) seasonal ionization in Es

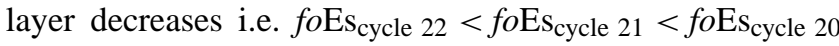
while in panel (d) all seasonal graphs show similar variation.

Figure 6 presents the seasonal variation of $h^{\prime} \mathrm{F} 2$ during four solar phases. All seasonal graphs show maximum virtual height in summer months and a trough at equinox months. Virtual heights increase as solar phases develop and as solar cycles increase. One can see dissymmetric minima during equinox months; in March equinox the trough is greater than October. Because the graphs present great difference, it can be noted that $h^{\prime} \mathrm{F} 2$ in Fig. $6 \mathrm{~b}$ of cycles 21 and 22 appear to follow similar variations. The above $h^{\prime} \mathrm{F} 2$ present a gap with $h^{\prime} \mathrm{F} 2$ of cycle 20 . This can be explained by the lack of data during the increasing phase of this cycle. 


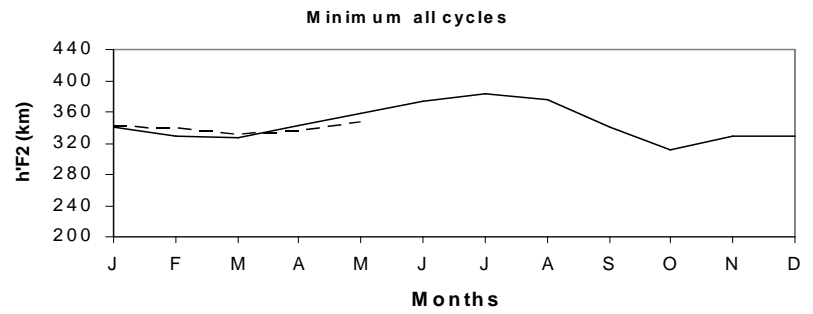

(a)

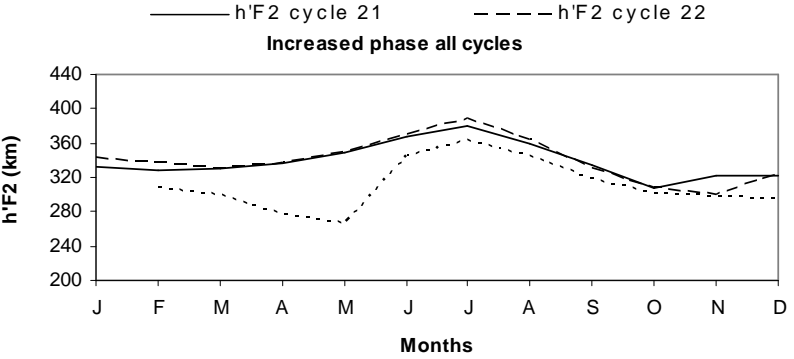

(b)

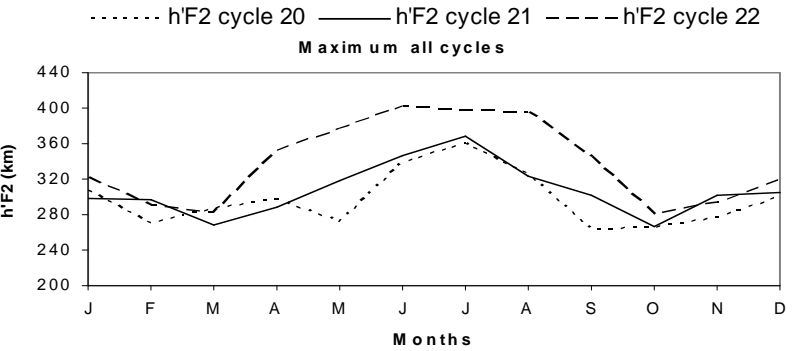

(c)
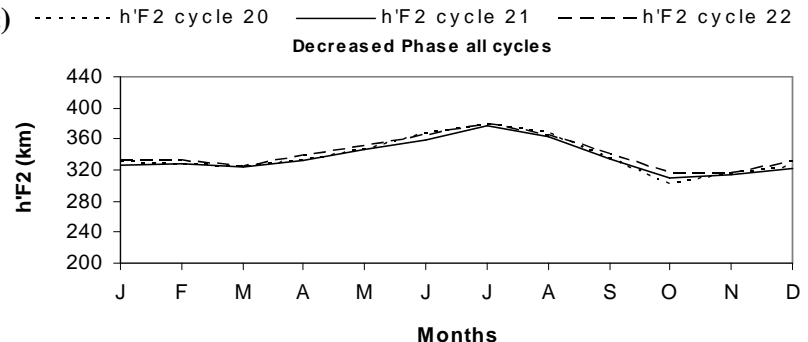

(d)

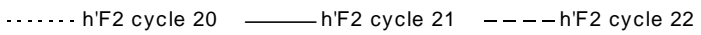

Fig. 6. Similar to Fig. 3 for $h^{\prime} \mathrm{F} 2$.

In panel (c) seasonal graphs of cycle 20 and 21 present similar variations and exhibit a gap related to cycle 22 seasonal graphs. All seasonal graphs in panel d show similar variations. It must be underlined that for cycle $21 h^{\prime} \mathrm{F} 2$ decreases as the solar phase develops.

Figure 7 presents seasonal variation of $h^{\prime} \mathrm{E}$ under four solar phases. There is no seasonal variation of the virtual height of the E layer. Figure $7 \mathrm{~b}$ shows that $h^{\prime} \mathrm{E}$ of solar cycle 20 is $20 \mathrm{~km}$ below $h^{\prime} \mathrm{E}$ of cycles 21 and 22 while in Fig. 7c, $h^{\prime} \mathrm{E}$ of cycle 20 is $15 \mathrm{~km}$ below $h^{\prime} \mathrm{E}$ of cycles 21 and 22 . On panel (d) such a difference is not observed. It can be underlined that $h^{\prime} \mathrm{E}$ of cycle 21 remains near $117 \mathrm{~km}$ through all phases and except the declining phase $h^{\prime} \mathrm{E}$ of cycle 22 stays near $117 \mathrm{~km}$ while that of cycle 20 is located at $107 \mathrm{~km}$. For the descending phase $h^{\prime} \mathrm{E}$ of cycle 20 increases from $107 \mathrm{~km}$

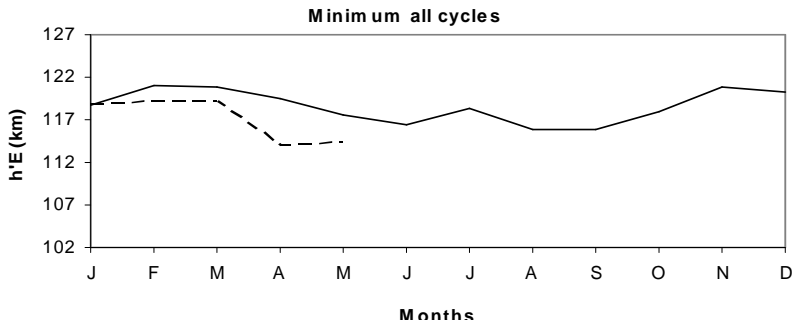

(a)

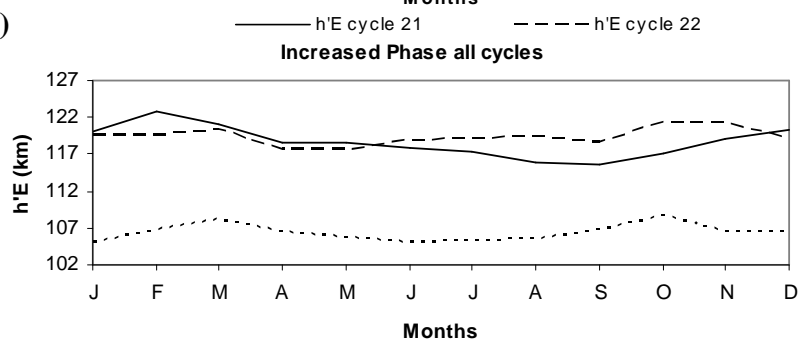

(b)
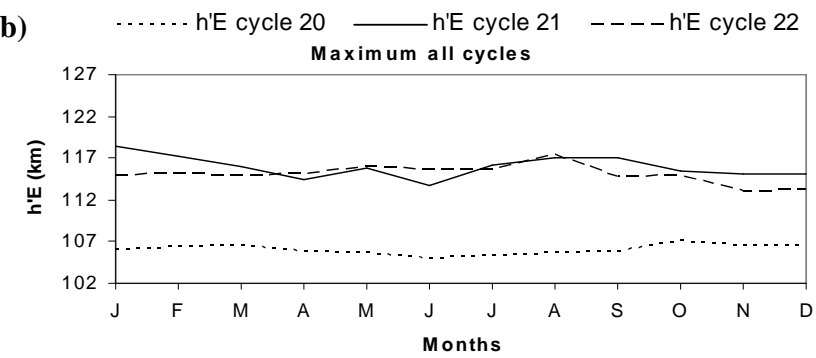

(c)

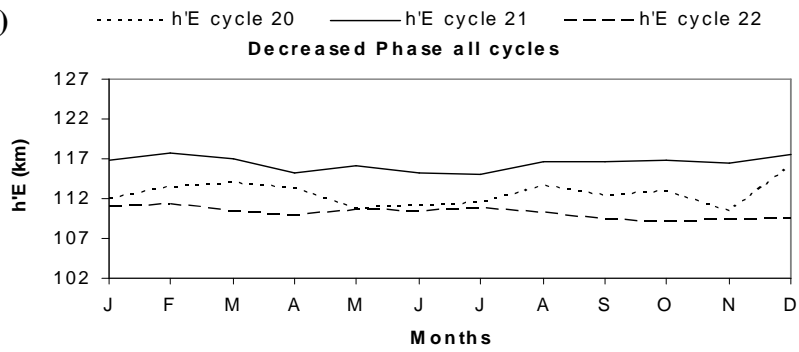

(d)

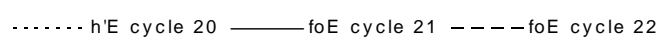

Fig. 7. Similar to Fig. 3 for $h^{\prime} \mathrm{E}$.

to $\sim 112 \mathrm{~km}$ while that of cycle 21 decreases from $117 \mathrm{~km}$ to $\sim 111 \mathrm{~km}$.

Figure 8 presents seasonal variation of $h^{\prime}$ Es during four solar phases. There is no particular seasonal variation of the virtual height of the Es layer. Through solar phases only seasonal graphs of cycles 20 and 21 are similar but in Fig. 8d, on can see that all the seasonal graphs are similar. $h^{\prime}$ Es presents its maximum in summer (May, June, July or August) and its minimum in equinox (March, April, September or October). Except in panels (a) and (d), $h^{\prime}$ Es of cycle 22 is greater than $h^{\prime}$ Es of the other cycles by $10 \mathrm{~km}$. It is important to underline that $h^{\prime}$ Es of the cycles 20 and 21 remain at $\sim 106 \mathrm{~km}$. In Fig. $8 \mathrm{~d} h^{\prime}$ Es for cycle 22 decreases by $10 \mathrm{~km}$, that of cycle 21 increases by $5 \mathrm{~km}$ while $h^{\prime}$ Es of cycle 20 remains at $106 \mathrm{~km}$. 


\subsection{Diurnal variation}

The diurnal variations of ionosphere parameters in West African equatorial region at Ouagadougou station have been studied by Ouattara (2009). As the diurnal variations are already known, we give here in Table 2 the mainly profiles characteristics and properties. Table 2 analysis shows that only h'F2 exhibits complex structure during solar maximum and $f \circ \mathrm{F} 2$ and $h^{\prime} \mathrm{F} 2$ present asymmetric peaks.

\section{Synthesis and discussion}

11-year behaviour observed in all ionosphere parameters (Fig. 1) is due to changes of solar and geomagnetic activity (Bremer, 2004).

Earth's atmosphere is ionized by X-ray and extreme ultraviolet (EUV) radiation (Rishbeth and Gariott, 1969; Jarvis, 2005). It is important to note that a nonlinear relationship exists between solar EUV flux and F10.7 during high solar activity (Lean, 1991; Balan et al., 1993; Huang and Cheng, 1996) while sunspot number (SSN) is closely related to F10.7. For that, a nonlinear relationship exists between EUV flux and SSN and could explain the different dependencies observed between ionosphere parameters and SSN. However, in our data there is a linear relationship between $f o \mathrm{~F} 2, f o \mathrm{~F} 1, h^{\prime} \mathrm{F} 1$ and $\mathrm{SSN}$. Table 1 shows the variation of this linear relationship. The correlation coefficient of $f o \mathrm{~F} 2$ decreases with solar cycle (from 0.997 for cycle 20 to 0.948 for cycle 22) while that of $f o \mathrm{~F} 1$ increases (from 0.850 for cycle 20 to 0.970 for cycle 22 ). $h^{\prime} \mathrm{F} 1$ correlation coefficient increases with solar cycle i.e. from 0.510 for cycle 20 to 0.792 for cycle 21 and from the above value to 0.896 for cycle 22 . The changes of ionosphere parameters correlation coefficients (Table 1) show that these ionosphere parameters have different evolution through the solar cycle. Such a result could be explained by the increasing greenhouse gas concentrations in the atmosphere (Roble and Dickinson, 1989; Rishbeth, 1990; Rishbeth and Roble, 1992; Hergel et al., 1996; Bremer, 2004).

Moreover the increase of geomagnetic activity during last three decades (Ouattara et al., 2008) and during last century (Mursula et al., 2006) also correlates with the results shown in Table 1, in so far as disturbed variations in E regions generally appear as an enhancement of $f o$ Es. Disturbed ionosphere parameters result from solar EUV (Tsurutani et al., 2005; Davis et al., 2001) and X emission (Davis et al., 2001; Grubor et al., 2005).

Solar events have been classified by Legrand and Simon (1989), Richardson et al. (2000) and Richardson and Cane (2002) and analysed by Ouattara and Amory Mazaudier (2009). Four classes have been obtained and are expressed as: slow solar wind activity, recurrent stream activity, fluctuating or "non clear activity" and shock activity. The occurrence of these classes through solar cycle is as follow-

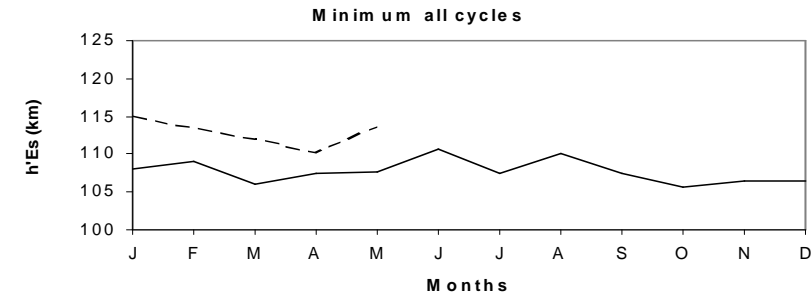

(a)

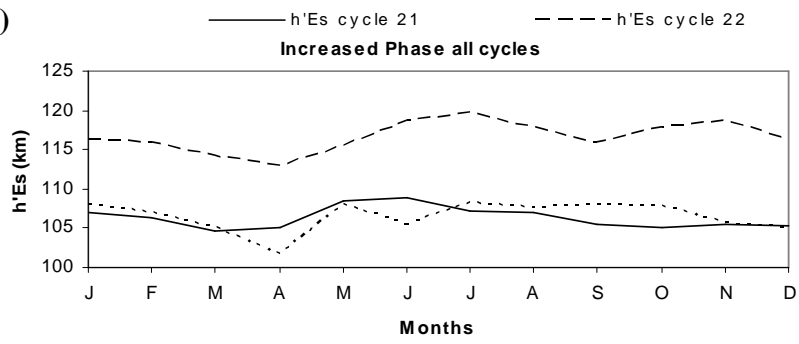

(b)
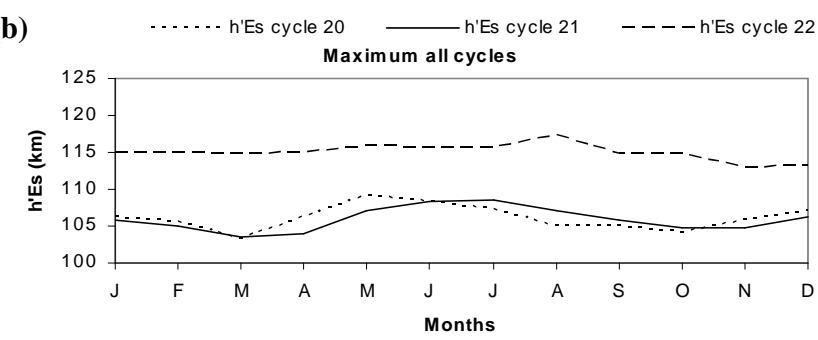

(c)
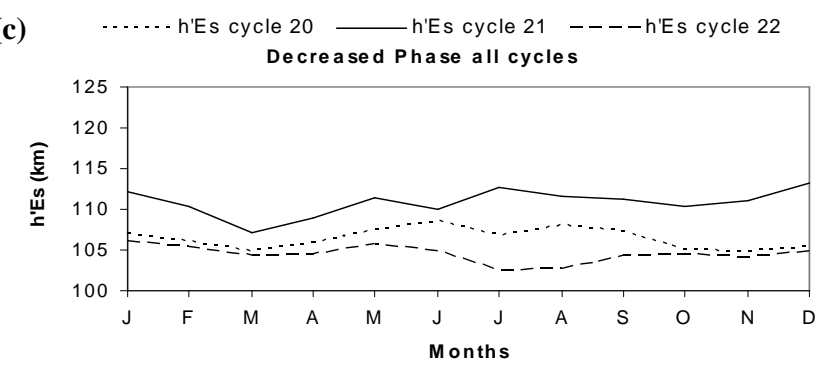

(d)

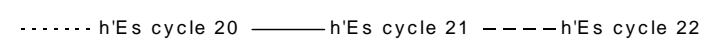

Fig. 8. Similar to Fig. 3 for $h^{\prime}$ Es.

ing: quiet days activity acts at minimum phase, fluctuating activity arises during increasing phase, shock event activity occurs during solar maximum and recurrent activity acts at declining phase. Thus, except maximum phase where SSC storms produce shock event activit, storms are generated by solar wind related to fluctuating activity and recurrent activity. The different solar events signatures appear in seasonal and diurnal profiles of ionospheric parameters. This will be underlined during the following discussion.

$f o \mathrm{~F} 2$ monthly evolution shows seminanual anomaly, winter or seasonal anomaly, annual or non-seasonal anomaly, and annual or seasonal asymmetry. $f o \mathrm{~F} 2$ semiannual anomaly in Ouagadougou area is a characteristic of $f o \mathrm{~F} 2$ (see Yonezawa, 1959; Rishbeth and Garriott, 1969; Yonezawa 1972; Huang and Cheng, 1996; Araujo-Pradere, 1997; Zou et al., 2000; Rishbeth et al., 2000; Zhang et al., 2005). This 
anomaly can be explained by transequatorial summer-winter neutral wind (Huang and Cheng, 1996) which increases the $\mathrm{O} / \mathrm{O}_{2}$ ratio in the winter hemisphere (Rees et al., 1987) and would lead to a greater local production rate of ionization in the winter hemisphere (Huang and Cheng, 1996).

$f o \mathrm{~F} 2$ seasonal anomaly observed at Ouagadougou has been early noted by Yonezawa (1959), Croom et al. (1960), Jacchia (1963) and VanZandt and Knecht (1964). Recently it has been underlined by Millward et al. (1996), Araujo-Pradere (1997), Zou et al. (2000), Rishbeth et al. (2000) and Zhang et al. (2004). This anomaly is attributed to temperature changes (Appleton, 1935), interhemispheric transport of ionisation (Rothwell, 1963), changes in the Sun-Earth distance (Yonezawa, 1959), seasonal change of $\mathrm{O} / \mathrm{N}_{2}$ concentration (Rishbeth and Setty, 1961; Wright, 1963; Rishbeth et al., 2000; Zhang et al., 2005) and the upward energy flux (Maeda et al., 1986). We note that for all phases of the sunspot solar cycle, we observe a winter anomaly (except during ascending phase (panel b). The absence of the winter anomaly during cycle 20 in Fig. $3 \mathrm{~b}$ may be the response of fluctuating wind stream activity.

Annual anomaly is characterized by December values which are greater than those in June (Zou et al., 2000). A possible cause of the annual anomaly is the changes in SunEarth distance (Zou et al., 2000; Buonsanto, 1986).

$f o \mathrm{~F} 2$ annual asymmetry does not have exactly the same amplitude everywhere. Hence, the annual variation in flux of the solar ionizing radiation cannot be the only factor (Rishbeth and Müller-Wodarg, 2006). The causes of this kind of asymmetry are possibly due to interplanetary corpuscular radiation (Yonezawa and Arima, 1959); and an annual variation of the neutral $\mathrm{O} / \mathrm{O}_{2}$ concentration ratio (Buonsanto, 1986).

Solar events effects can be identified in $f \circ \mathrm{F} 2$ monthly profiles. In fact, during quiet condition, $f o \mathrm{~F} 2$ presents winter and semiannual anomalies, with equinoctial asymmetric peaks in March/April and October. Winter anomaly appears during fluctuating activity, the increasing of the ionization and equinoctial peaks in April and October. When shock activity occurs, ionization increases with equinoctial peaks in April and October. Under recurrent activity there is no asymmetry peaks, ionisation increases and the peaks are located in March and October.

By looking at $f o \mathrm{E}$ maximum values on Fig. 4, we must note the variability of this parameter through the year and during the three solar cycles. This complex structure is not surprising because the E layer is produced not only by monochromatic radiation but also by a variety of wavelength (including X-rays and EUV) (Rishbeth and Garriott, 1969). This annual variation presents no anomaly. In Fig. 4 it seems impossible to detect any fluctuating activity effect but one must conclude that the shock activity (panel c) and wind stream activity (panel d) act to decrease E layer ionization. It must be noted that the parallel variability between all the graphs in panel (d) is a mark of recurrent storm. So by ex- cluding the ionisation rate during wind stream activity, the $f o$ E profile is independent from solar cycle.

Figure 5 shows the decrease of $f o$ Es as solar cycle increases. Its maximum values confirm this tendency. This could be interpreted as the effect of greenhouse gases because the decreasing of $f o \mathrm{E}$ without considering geomagnetic and solar effects was attributed to greenhouse gases (Bremer, 2004; Hall et al., 2007). foEs profile is typical, because Es occurs most often in summer and presents secondary peak in the winter (Hawk, 2001). The only characteristic which can be noted here is that the effect of wind stream activity in $f o$ Es is fairly independent from solar cycle because graphs develop almost together.

The variations of $h^{\prime} \mathrm{F} 2$ given by Fig. 6 presents no anomaly. From Fig. 6 one must note that wind stream activity (panel d) acts in the same way during solar cycle than during quiet conditions (panel a), graphs are similar and the troughs are located in March and October. The only difference between the effect of fluctuating activity and the shock one is the gap between graphs during summer months.

As we have underlined in the case of $f o \mathrm{E}, h^{\prime} \mathrm{E}$ profile shows complex structure (Fig. 7). It is difficult to differentiate shock activity effect from fluctuating one. But the absence of gap on graphs permits us to make two groups. Slow and recurrent activities act when there is no gap and the others act when there is a gap.

In Fig. 8 only the presence of a gap permits us to separate solar events activity in two groups like in Fig. 7.

\section{Concluson}

In this study, climatology of ionospheric in West African Equatorial region is performed through three solar cycles (cycles 20, 21 and 22). We take into account the four solar cycle phases such as minimum phase, increasing phase, maximum phase and decreasing phase.

Yearly variation of ionospheric parameters shows 11year cycle evolution. There is parallel behaviour between: (1) sunspot number and $f o \mathrm{~F} 2$ (regression coefficient: 0.951); (2) sunspot number and $f o \mathrm{~F} 1$ (regression coefficient: 0.904); (3) sunspot number and $h^{\prime} \mathrm{F} 1$ (regression coefficient: 0.727). Moreover F1 layer shows increasing trend from solar cycle 20 to solar cycle 22. Bremer (2004) showed the same trend of the $f o \mathrm{~F} 1 . h^{\prime} \mathrm{F} 2$ is fairly anti correlated with sunspot number (regression coefficient 0.333 ) while there is no correlation between ionospheric parameters such as $f o \mathrm{E}, f o \mathrm{Es}$, $h^{\prime} \mathrm{E}$ and $h^{\prime}$ Es and sunspot number. $f o \mathrm{E}$ decreases with solar activity. In fact, the 11-year running arithmetic mean of this parameter gives 0.755 as an anti correlation coefficient. foEs also decreases during cycles 20 and 21; 11-year running arithmetic mean gives 0.918 as an anti correlation coefficient. From solar cycle 20 to solar cycle 22, seasonal variation shows semiannual, winter and annual anomaly variation of $f o \mathrm{~F} 2$ parameter and no anomaly for the others. 
The main results of our work are the relation between seasonal variation and solar events such as slow solar wind activity, fluctuating activity, recurrent activity and shock activity.

Diurnal variation of $f o \mathrm{E}$ shows that it increases with solar phases and exhibits a time delay between the graph of cycle 22 and the others. We must underline here that we have no explanation for this latest observation.

Green house gases effects in diurnal variation have been identified in ionosphere.

These new results open the way to theoretical analysis of the sun's interactions on the magnetosphere and ionosphere including the solar events.

Acknowledgements. The authors thank Ecole Nationale Supérieure de Télécommunication de Bretagne (ENST Bretagne) who provides ionospheric parameters data and the NGDC data center for the values of sunspot number.

The authors also thank the ionosphere Topical Editor and the Editorial Executive of Annales Geophysicae for their useful comments, and referees suggestions for improving the present paper English.

Topical Editor M. Pinnock thanks two anonymous referees for their help in evaluating this paper.

\section{References}

Adeniyi, J. O. and Adimula, I. A.: Comparing the F2 layer model of IRI with observations at Ibadan, Adv. Space Res., 15, 141-1444, 1995.

Adeniyi, J. O. and Radicella, S. M.: Diurnal variation of ionospheric profile parameters B0 and B1 for an equatorial station at low solar activity, J. Atmos. Solar-Terr. Phys., 60, 381-385, $1998 \mathrm{a}$.

Adeniyi, J. O. and Radicella, S. M.: Variation of bottomside profile parameters B0 and B1 at high solar activity for a equatorial station, J. Atmos. Solar-Terr. Phys., 60, 1123-1127, 1998 b.

Amory-Mazaudier, C., Le Huy, M., Cohen, Y., Doumbia, V., Bourdillon, A., Fleury, R., Fontaine, B., Ha Duyen, C., Kobea, A., Laroche, P., Lassudrie-Duchesne, P., Le Viet, H., Le Truong, T., Luu Viet, H., Menvielle, M., Nguyen Chien, T., Nguyen Xuan, A., Ouattara, F., Petitdidier, M., Pham Thi Thu, H., Pham Xuan, T., Philippon, N., Tran Thi, L., Vu Thien, H., and Vila, P.: SunEarth System Interaction studies over Vietnam: an international cooperative project, Ann. Geophys., 24, 3313-3327, 2006, http://www.ann-geophys.net/24/3313/2006/.

Appleton, E. V. and Barnett, M. A. F.: On wireless interference phenomena between ground waves and waves deviated by upper atmosphere, Proc. R. Soc., 113, 450-438, 1926.

Araujo-Pradere, E. A.: foF2 frequency bands in el cerrillo, Mexico during magnetically quiet conditions, Rev. Bras. Geof., 15, 2, doi:10.1590/S0102-261X1997000200006, 1997.

Balan, N., Bailey, G. J., and Jayachandran, B.: Ionospheric evidence for a nonlinear relationship between the solar EUV. and $10.7 \mathrm{~cm}$ fluxes during an intense solar cycle, Planet. Space Sci., 41, 141-145, 1993.

Bilitza, D., Obrou, O. K., Adeniyi, J. O., and Oladipo, O.: Variability of $f_{o} \mathrm{~F} 2$ in the equatorial ionosphere, Adv. Space Res., 34, 1901-1906, 2004.
Bremer, J.: Investigations on long-term trends in the ionosphere with world-wide ionosonde observation, Adv. Radio Sci., 2, 253258, 2004, http://www.adv-radio-sci.net/2/253/2004/.

Breit, G. and Tuve, M. A.: A Test of the existence of the conducting layer, Phys. Rev., 28, 554-575, 1926.

Buonsanto, M. J.: Possible effects of the changing Earth-Sun distance on the upper atmosphere, S. Pacific J. Nat. Sci., 8, 58-65, 1986.

Chaman, L.: Contribution to F2 layer ionization due to the solar wind, J. Atmos. Solar-Terr. Phys., 59(17), 2203-2211, 1997.

Chaman, L.: Solar wind and equinoctial maxima in geophysical phenomena, J. Atmos. Solar-Terr. Phys., 60, 1017-1024, 1998.

Chapman, S.: The absorption and dissociative or ionizing effect of monochromatic radiation in an atmosphere on a rotating Earth, Proc. Phys. Sot., 43, 26-45, 1931.

Chapman, S. and Bartels, J.: Geomagnetism, Oxford University Press New York, 1940.

Croom, S. A., Robbins, A. R., and Thomas, J. O.: Variation of the electron density in the ionosphere with magnetic dip., Nature, 185, 902-903, 1960.

Davies, K.: Ionospheric Radio Propagation, National Bureau of Standards Monograph, 80, 1965.

Fuller-Rowell, T. J., Codrescu, M. C., and Wilkinson, P.: Quantitative modeling of the ionospheric response to geomagnetic activity, Ann. Geophys., 18, 766-781, 2000, http://www.ann-geophys.net/18/766/2000/.

Hall, C. M. and Hansen, T. L.: 20th Century operation of the Troms $\phi$ ionosonde, Adv. Polar Upper Atmos. Res., 17, 155-166, 2003.

Hall, C. M., Brekke, A., and Cannon, P. S.: Climatic trends in Eregion critical frequency and virtual height above Troms $\left(70^{\circ} \mathrm{N}\right.$, $\left.10^{\circ} \mathrm{E}\right)$, Ann. Geophys., 25, 2351-2357, 2007, http://www.ann-geophys.net/25/2351/2007/.

Hawk, M.: Mid-Latitude Sporadic-E - A Review, 12 November 2001, www.anarc.org/wtfda/sporade.pdf, 2001.

Hergel, C. G., von Storch, H., Hasselmann, K., Sauter, B. D., Cubasch, U., and Jones, B. D.: Detected greenhouse-gas induced climate change with an optimal fingerprint method, J. climate, 9, 2281-2306, 1996.

Huang Chun-ming: A certain behaviour of the inospheric F2 region at low latitudes, Radio. Sci., 9(5), 519-532, 1974.

Huang Yinn-Nien and Cheng, K.: Solar cycle variations of the equatorial ionospheric anomaly in total electron content in the Asians region, J. Geophys. Res., 101(A11), 24513-24520, 1996.

Jacchia, L. G.: Variations in the earth's upper atmosphere as revealed by satellite drag, Rev. Mod. Phys., 35, 973-991, 1963.

Jarvis, M. J.: Observed tidal variation in the lower thermosphere through the $20^{\text {th }}$ century and the possible implication of ozone depletion, J. Geophys. Res., 110, A04303, doi:10.1029/2004JA010921, 2005.

Lean, J.: Variation in the Sun's radiation output, Rev. Geophys., 29, 505-535, 1991.

Legrand, J. P. and Simon, P. A.: Solar cycle and geomagnetic activity : A review for geophysicists. Part I. The contributions to geomagnetic activity of shock waves and of the solar wind, Ann. Geophys., 7(6), 565-578, 1989.

Madea, K., Hedin, A. E., and Mayr, H. G.: Hemispherical asymmetries of the thermospheric semiannul oscialltion, J. Geophys. Res., 91, 4461-4470, 1992. 
Millward, G. H., Rishbeth, H., Fuller-Rowell, T. J., Aylward, A. D., Quegan, S., and Moffert, R. J.: Ionospheric F2 layer seasonal and semiannual variations, J. Geophys. Res., 101(A3), 5149-5156, 1996.

Obrou, O. K.: Ionosphère équatoriale : contribution à l'amélioration du modèle " international reference Ionosphere " (IRI), Thèse de doctorat d'état en physique, Université de Cocody-Abidjan, UFR SSMT, 204 p., 2008

Ouattara, F., Amory-Mazaudier, C., Menvielle, M., Simon, P., and Legrand, J.-P.: On the long term change in the geomagnetic activity during the 20th century, Ann. Geophys., 27, 2045-2051, 2009, http://www.ann-geophys.net/27/2045/2009/.

Ouattara, F. and Amory-Mazaudier, C.: Solar-geomagnetic activity and Aa indices toward a Standard, J. Atmos. Solar-Terr. Phys., in press, doi:10.1016/j.jastp.2008.05.001, 2009.

Ouattara, F.: Contribution à l'étude des relations entre les deux composantes du champ magnétique solaire et l'ionosphère équatoriale, Thèse de Doctorat d'état, UCAD, 340 p., 2009

Rees, D. T., Fuller-Rowell, J., Quegans, S., Moffett, R. J., and Bailey, G. J.: Thermospheric dynamics: Understanding the unusual disturbances by mean of simulations with a fully-coupled global thermospheric/high latitude ionosphere model, Ann Geophys., Ser. 5A. 303-328, 1987.

Richardson, I. G., Cliver, E. W., and Cane, H. V.: Sources of geomagnetic activity over the solar cycle: relative importance of coronal mass ejections, high-speed streams, and slow solar wind, J. Geophys. Res., 105(A8), 18200-18213, 2000.

Richardson, I. G. and Cane, H. V.: Sources of geomagnetic activity during nearly three solar cycles (1972-2000), J. Geophys. Res., 107(A8), 1187, 2002.

Rishbeth, H. and Garriott, O. K.: Introduction to ionospheric physics, Academic Press, New York, 1969.

Rishbeth, H. and Setty, C. S. G. K.: The F-layer at sunrise, J. Atmos. Terr. Phys, 20, 263-276, 1961.

Rishbeth, H.: A greenhouse effect un the thermosphere?, Planet. Space Sci., 38, 945-948, 1990.

Rishbeth, H.: The centenary of solar-terrestrial physics, J. Atmos. Solar-Terr. Phys., 63, 1883-1890, 2001.

Rishbeth, H. and Roble, R. G.: Cooling of the upper atmosphere by enhanced greenhouse gases-modelling of the thermospheric and ionospheric effects, Planet. Space Sci., 40, 1011-1026, 1992.

Rishbeth, H. and Clilverd, M.: Long-term change in the upper atmosphere greenhouses gases-Modelling of the termospheric and ionospheric effects, Planet. Space, Sci., 40, 1011-1026, 1999.
Rishbeth, H. and Müller-Wodarg, I. C. F.: Why is there more ionosphere in January than in July? The annual asymmetry in the F2-layer, Ann. Geophys., 24, 3293-3311, 2006, http://www.ann-geophys.net/24/3293/2006/.

Rishbeth, H., Müller-Wodarg, I. C. F., Zou, L., Fuller-Rowell, T. J., Millward, G. H., Moffett, R. J., Idenden, D. W., and Aylward, A. D.: Annual and semiannual variations in the ionospheric F2-layer: II. Physical discussion, Ann. Geophys., 18, 945-956, 2000, http://www.ann-geophys.net/18/945/2000/.

Roble, R. G. and Dickinson, R. E.: How will changes in carbon dioxide and methane modify the mean structure of the mesosphere and thermosphere?, Geophys. Res. Lett., 16, 1441-1444, 1989.

Rothwell, P.: Diffusion of ions between F layers at magnetic conjugate points, in Proc. International Conference on the Ionosphere, Institute of Physics and Physical Society, London, 217221, 1963.

Schröder, W.: Comment on the paper" The centenary of solar terrestrial physics", J. Atmos. Solar-Terr. Phys., 64, 1675-1677, 2002.

Simon, P. A. and Legrand, J. P.: Solar cycle and geomagnetic activit : A review for geophysicists. Part II. The solar sources of geomagnetic activity and their links with susnspot cycle activity, Ann. Geophys., 7(6), 579-594, 1989.

Thomas, J. A. and Smith, E. K.: A survey of the present knowledge of sporadic-E ionization, J. Atmos. Terr. Phys., 13, 295314, 1959.

Walker, G. O.: Electron content and topside plasma temperature studies at low latitudes during a period from sunspot minimum to sunspot maximum, J. Atmos. Terr. Phys., 33, 1041-1053, 1971.

Wright, J. W.: The F-region seasonal anomaly, J. Geophys. Res., 68, 4379-4381, 1963.

Yonezawa, T.: On the seasonal and non-seasonal annual variations and the semiannual variation in the noon and midnight densities of the F2 layer in middle latitudes II, J. Radio Res. Labs. Japan, 6, 651-668, 1959.

Zhang, S. R., Holt, J. M., Anthony, P., Eyken, V., McCready, M., Amory-Mazaudier, C., Fukao, S., and Sulzer, M.: Ionospheric local model and climatology from long-term databases of multiple incoherent scatter radars, Geophys. Res. Lett., 32, L20102, doi.1029/2005GL023603, 2005.

Zou, L., Rishbeth, H., Müller-Wodarg, I. C. F., Aylward, A. D., Millward, G. H., Fuller-Rowell, T. J., Idenden, D. W., and Moffett, R. J.: Annual and semiannual variations in the ionospheric F2-layer. I. Modelling, Ann. Geophys., 18, 927-944, 2000, http://www.ann-geophys.net/18/927/2000/. 